\title{
Organizational aspects of Global Therapy
}

\section{Diego Ettore Liberati*}

Dipartimento di Elettronica, Research Director National Research Council of Italy, Milano, Italy

In order to improve therapy, to design the best drugs is of course helpful. But!:

Imagine an elder patient who developed a breast cancer still without metastases. The sanitary system takes weeks to follow the standard protocol. The patient is first suggested hormone therapy. Unfortunately, she is unresponsive. The oncologic decision is then to undergo surgery, that would be quite resolutive, at least for the next few years, unless the patient die under it, which would be sad, but probably not the worst scenario. In the meanwhile, of such a month of protocol, the patient develops lymphatic first involvement. At this point, surgery will still probably used, but it will not be resolutive, thus further implying a chemotherapy follow up, for the joy of pharma companies and maybe of physicians, and the suffering of the patients and her relatives.

My mother seems to be today in this very situation. Is it the best organizational mode we could expect as tax-payers?
Copyright: (C2018 Liberati DE. This is an open-access article distributed under the terms of the Creative Commons Attribution License, which permits unrestricted use, distribution, and reproduction in any medium, provided the original author and source are credited.
${ }^{*}$ Correspondence to: Diego Ettore Liberati, $\mathrm{PhD}$, Research Director National Research Council of Italy, Information \& Control 4 Systems Biology @ IEIIT, Dipartimento di Elettronica, Informazione e Bioingegneria, Politecnico Piazza Leonardo da Vinci 32, Milano, Italy, E-mail: diego.liberati@polimi.it

Received: April 12, 2018; Accepted: May 02, 2018; Published: May 30, 2018 